\title{
Is the Integrated Information Theory of Consciousness Compatible with Russellian Panpsychism?
}

\author{
Hedda Hassel Mørch
}

Erkenntnis (2018)

Penultimate draft - please refer to published version for citation.

\begin{abstract}
The Integrated Information Theory (IIT) is a leading scientific theory of consciousness, which implies a kind of panpsychism. In this paper, I consider whether IIT is compatible with a particular kind of panpsychism known as Russellian panpsychism, which purports to avoid the main problems of both physicalism and dualism. I will first show that if IIT were compatible with Russellian panpsychism, it would contribute to solving Russellian panpsychism's combination problem, which threatens to show that the view does not avoid the main problems of physicalism and dualism after all. I then show that the theories are not compatible as they currently stand, in view of what I call the coarse-graining problem. After I explain the coarse-graining problem, I will offer two possible solutions, each involving a small modification of IIT. Given either of these modifications, IIT and Russellian panpsychism may be fully compatible after all, and jointly enable significant progress on the mind-body problem.
\end{abstract}

\section{Introduction}

Panpsychism is the view that every physical thing is associated with consciousness. More precisely, it is the view that every physical thing is either (1) conscious as a whole, (2) made of parts which are all conscious, or (3) itself forms part of a greater conscious whole. Humans and animals (or certain areas of human and animal brains) are conscious in the first sense- our consciousness is unified, or has a single, subjective point of view. Panpsychists typically think fundamental particles, such as quarks, are conscious in this sense too. Artifacts and arbitrary aggregates, such as tables, chairs and heaps, may be conscious only in the second sense; that is, in virtue of being made of particles that are conscious in the first sense. Particles and neurons that form part of human and animal brain areas which are conscious in the first sense may be conscious only in the third sense. By "consciousness", panpsychists mean phenomenal 
consciousness, i.e., the property of having some form of subjective experience, or of there being something that it is like to be something. ${ }^{1}$

Panpsychism has recently received new attention in both philosophy and neuroscience. In philosophy of mind, it has been argued that a version of panpsychism, panpsychist Russellian monism (named after Bertrand Russell, for reasons that will be explained below), is able to avoid the most serious problems that confront the traditional main positions in the field, physicalism and dualism (Nagel 1979; Strawson 2006a; Alter and Nagasawa 2012; Chalmers 2015). For physicalism, this is the problem of the epistemic gap-aspects of which are highlighted by the knowledge argument (Jackson 1982, 1986) and the conceivability argument (Kripke 1980; Chalmers 1996). For dualism, it is the problem of mental causation (Kim 1988). In neuroscience, the Integrated Information Theory (IIT) (Tononi 2004, 2008, 2011; Tononi, Albantakis, and Oizumi 2014) is a new fundamental theory of consciousness which has proved to have significant explanatory and predictive power, and it is currently among the leading theories in the field. According to IIT, consciousness is correlated with integrated information, also referred to as $\Phi$ (phi). Information, as IIT defines it, measures the extent to which a system causally constrains its own immediate past and future state. ${ }^{2}$ Integration measures the extent to which this information depends on the causal interconnectivity of the system's parts. ${ }^{3}$ Since

\footnotetext{
${ }^{1}$ Consciousness does not require the capacity for, e.g., thought, abstraction or self-awareness. These can be regarded as advanced, complex forms of consciousness and reserved for advanced, complex physical systems. Therefore, panpsychism does not entail that particles think or are self-conscious.

${ }^{2}$ I.e., how much can you know about the previous and next state of the system by looking only at its present state, given that all external influences are fixed (and you know all the relevant causal laws)? The measure also takes into account the number of possible states a system can be in - the greater the number of possible states of a system, the more past and future states can be ruled out by the current state, which in IIT corresponds to higher information.

${ }^{3}$ I.e., how much information would you lose by dividing the system in two, and (unidirectionally) cutting all connections from one half to the other? Computers, of the kind we make today, might in principle have the same quantity of information as human brains - they could have a similar number of possible states and causally constrain their own past and future states to a similar degree. But in today's computers, the connectivity between transistors and modules is limited and often feed-forward. There will therefore be ways of cutting these systems in two that will not result in significant loss of information, such as a unidirectional cut from the output level to the input level of a feed-forward structure. In the brain, in contrast, especially in (parts of) the cerebrum, there is
} 
“even simple matter has a modicum of $\Phi ”$ (Koch 2012: 132), IIT implies panpsychism in the sense defined above. ${ }^{4}$

IIT sometimes encounters the objection that although it may appear to account well for empirical data about human consciousness - such as the absence of consciousness during deep sleep, general anesthesia, epileptic seizures, and in regions of the brain such as the cerebellum, all of which correlate with low values of $\Phi$ (Tononi and Koch 2015; Tononi et al. 2016) - it cannot be correct because panpsychism is absurd (Searle 2013). But if Russellian panpsychism is able to avoid the main philosophical problems of both physicalism and dualism, IIT's panpsychism should be regarded as a feature, not a bug. IIT could claim philosophical support in virtue of being the only current neuroscientific theory compatible with the most plausible solution to the mind-body problem.

\footnotetext{
significant feedback connectivity — neurons mutually constrain a vast number of other neurons. Cutting connections between two parts of the cerebrum in any direction is therefore going to lead to a great loss of information. Hence, the cerebrum has a much higher level of integrated information $(\Phi)$. For a more detailed introduction to IIT, see Tononi and Koch (2015). For a full description of the latest version of the theory, see Tononi, Albantakis, and Oizumi (2014).

4 Tononi explicitly acknowledges that IIT comes close to panpsychism (Tononi 2008: 236; Tononi and Koch 2015: 11). He is careful to distinguish IIT's panpsychism from the universalist form of panpsychism (to be discussed further below) according to which all things, including artifacts and aggregates, are conscious as individuals, i.e., in the first sense. But IIT still implies that all things are conscious at least in the sense of being made of conscious parts or forming part of greater conscious whole, i.e., in the second or third sense. As Koch notes, "protons and neutrons consist of a triad of quarks that are never observed in isolation. They constitute an infinitesimal integrated system" (Koch 2012: 132). If protons and neutrons have some $\Phi$, then these particles will be conscious either individually or as parts of systems with greater $\Phi$ (such as atoms or brains). Furthermore, all things that are made of protons and neutrons will at least be conscious in the sense of being made of conscious parts. And if quarks are always part of integrated systems like protons and neutrons, they will necessarily be conscious in the sense of forming part of a greater conscious system.

One might wonder about other fundamental particles, such as electrons, that unlike quarks may be found in isolation. Would they be conscious? This question does not have a straightforward answer, because IIT defines $\Phi$ only for systems that can be regarded as composed of discrete elements. Physics is now widely taken to support the view that particles are really excitations in continuous fields, hence, IIT does not directly apply to fundamental physics. Barrett (2014) has given one proposal for how IIT can be extended to fundamental physics, which explicitly entails that isolated electrons will have some $\Phi$, and therefore some consciousness (2014: 4), roughly because field excitations are complexly structured events. However, it is not guaranteed that other ways of extending IIT to physics will have the same result. Therefore, IIT can only be said to imply (complete) panpsychism in the sense of strongly suggesting it; it does not strictly entail it. In view of this, the central question of this paper may be more precisely put as: "Is IIT, if extended to fundamental physics in some way that entails (complete) panpsychism, compatible with Russellian panpsychism?".
} 
But not everyone agrees that Russellian panpsychism can solve the mind-body problem. The main objection to Russellian panpsychism is based on what is known as the combination problem (James 1890; Seager 1995). ${ }^{5}$ The combination problem is the problem of explaining how complex consciousness, of the kind we know from our own case, could result from the combination of entities with simple consciousness, i.e., the particles that constitute our brain and possess (according to panpsychism) rudimentary forms of consciousness. According to the objection, the combination problem gives rise to further problems which are strongly analogous the main problems of physicalism and dualism (Goff 2006, 2009; Chalmers 2015, 2016).

At first glance, it appears IIT can help Russellian panpsychism solve the combination problem. The precise claim of IIT is that a system is conscious, in the first sense, if and only if it is a maximum of $\Phi$, i.e., if the system has higher $\Phi$ than any of its own parts as well as any larger bigger system of which it is part. This is IIT's Exclusion postulate - consciousness does not overlap. This means that whenever the $\Phi$ of a system surpasses the $\Phi$ of the parts, the system goes from being conscious in the second, aggregative sense to being conscious in the first, unified sense. This explains how mental combination occurs, at least to a certain extent. Tononi and Koch imply $(2015: 11,13)$ that IIT may offer a complete solution to the combination problem in and of itself. But one might also regard IIT as merely a contributing part of a complete solution when taken together with other proposed solutions to the problem. Other proposed solutions include the phenomenal bonding view (Goff 2009, 2016) and the fusion view (Seager 2010, 2016; Mørch 2014). These proposals look promising in purely metaphysical respects, but both arguably fail to show what could possibly constitute an empirical correlate of combination. IIT shows what this correlate could be, namely maximal $\Phi$.

\footnotetext{
5 The most common objection to panpsychism is probably "the incredulous stare". The most serious objection is the combination problem.
} 
Unfortunately, however, a solution to the combination problem in terms of IIT would not be straightforward. In order to solve the combination problem, IIT needs to be compatible with Russellian panpsychism, not just panpsychism in general. Panpsychism could also be combined with dualist or physicalist metaphysics, ${ }^{6}$ but would then have no advantage compared to standard physicalism or dualism with respect to the mind-body problem. And there are some indications that IIT is compatible only with dualist or physicalist panpsychism. This would be bad news for both IIT and Russellian panpsychism: IIT could no longer claim that its panpsychism is in fact a philosophical advantage, and Russellian panpsychism would retain its combination problem.

In this paper, I will explain the main indication of this disappointing result, a problem which I will call the coarse-graining problem. I will show that this is not a surface problem: IIT and Russellian panpsychism are in fact incompatible as the theories currently stand. But the conflict could still be resolved by introducing some substantive new principles. I will suggest two candidates for such principles: first, a modification of IIT's Exclusion postulate (not abolition, as some have called for (Schwitzgebel 2015)); second, a modification of IIT's principle for determining the spatiotemporal grain of conscious systems. My arguments, if successful, will not support a fully satisfactory solution to the combination problem in terms of IIT, but they should give reason for optimism and motivate further research into this approach.

I will begin by explaining the metaphysics of Russellian panpsychism and the combination problem in more detail. I will then discuss how IIT could help solve the combination problem, either on its own, or combined with the phenomenal bonding or fusion view. I will then present

\footnotetext{
${ }^{6}$ Dualist panpsychism would be the view that every physical thing is connected with a mental substance (or wholly non-physical mental properties) via fundamental psychophysical laws of nature. Physicalist panpsychism would be the view that consciousness is to be reductively identified with a ubiquitous physical property (such as integrated information understood in a purely functionalist way).
} 
the coarse-graining problem, which shows that the views are in fact incompatible, followed by my two proposals for how to resolve the problem.

\section{Physicalism, Dualism and Russellian Panpsychism}

According to Russellian panpsychism, consciousness is associated with every physical thing because consciousness constitutes the intrinsic nature of physical structure. As Bertrand Russell noted (1927), physics (or the physical sciences) only describes relational or structural properties - how physical things relate to other things, but not how they are in and of themselves. But phenomenal properties, which characterize what it is like to be in conscious states, seem to be intrinsic — we know what they are like in and of themselves, independently of how they relate to other properties. Furthermore, physical structure or relations need realizers or relata with intrinsic properties, and phenomenal properties seem to be the only intrinsic properties we know. Russellian panpsychists infer from this that consciousness could be the realizer of all physical structure or an intrinsic property of every entity described by physics in purely relational terms (Seager 2006; Alter and Nagasawa 2012). ${ }^{7}$

As noted, the main attraction of Russellian panpsychism is that it offers a solution to the mindbody problem which appears to avoid the main difficulties of physicalism and dualism at once. Physicalism is the view that phenomenal properties are identical to, or constituted by, physical properties - where physical properties are understood as the kind of properties that can in principle be exhaustively described by physics (or the physical sciences). Its main problem is that it appears impossible in principle to see any entailment from the existence of any physical

\footnotetext{
${ }^{7}$ Note that Russell himself ultimately concluded that the intrinsic character of physical structure is not mental but neutral, i.e., neither mental nor physical. The more general view that the intrinsic character of physical structure is either neutral, protomental or mental is known as Russellian monism. Despite its name, central elements of Russellian monism predate Russell. Notable predecessors include Leibniz (see Pereboom 2015), Schopenhauer (see especially 1966a, pp. 119-127 and 1966b, pp. 191-200), James (1890, 1912), Mach (1886, 1894, 1905) and arguably Kant (especially given the reading defended in Langton 1998). Furthermore, the contemporary version of the view may not fully correspond to Russell's own neutral monism (Stubenberg 2015; but see Wishon 2015 for a different interpretation).
} 
properties to the existence of any phenomenal properties — something which should be possible if the latter were indeed identical to or constituted by the former (Chalmers 2003) (assuming we have an adequate grasp of the nature of both the phenomenal and the physical (see Goff 2016)). In the absence of such an entailment, we are able to conceive of the phenomenal and the physical coming apart, as highlighted by the conceivability argument (i.e., zombie argument) (Chalmers 2009). Also, someone who knew all physical properties would not be able to deduce the existence of phenomenal properties, as highlighted by the knowledge argument (Jackson 1982).

Dualism is the view that phenomenal properties are non-physical, and connected to physical properties by fundamental causal laws. Its main problem is the threat of epiphenomenalism in view of the principle of physical causal closure, which holds that every physical event (that has a cause) has a sufficient physical cause. This principle precludes non-physical properties from playing any non-overdetermining causal role in the physical world. The principle is widely regarded as having solid empirical and methodological support (Papineau 2001), and it seems implausible that some physical events are systematically overdetermined by both phenomenal and physical causes. The only option for dualists who accept physical causal closure and deny overdeterminism is to embrace epiphenomenalism, i.e., deny the causal efficacy of the phenomenal.

Russellian panpsychism avoids physicalism's main problem because it denies that phenomenal properties are identical with or constituted by physical properties. Instead, it takes phenomenal properties to constitute physical properties, as their intrinsic realizers. It also avoids dualism's main problem, because this inverted constitution relation avoids epiphenomenalism, overdeterminism, and violation of physical causal closure. If phenomenal properties realize physical structure, they are essential to the physical world: causally efficacious physical properties could not even exist without intrinsic properties to realize them, and there are no 
non-phenomenal intrinsic properties (that we know of) which already realize them and so overdetermine their existence. At the same time, it leaves physical structure unchanged so that the physical world remains causally closed from the structural point of view. ${ }^{8}$

\section{The Combination Problem}

The combination problem is the problem of explaining how complex macro-consciousness, of the kind we know from our own case, can result from the combination of simple entities with simple micro-consciousness. Constitutive panpsychism is the view that complex consciousness is constituted by micro-consciousness, or in other words, that a complex conscious experience is nothing over and above a set of simple conscious experiences causally or spatiotemporally related in some particular way. This view faces a problem analogous to physicalism's problem of the epistemic gap: it appears impossible in principle to see any entailment from the existence of micro-conscious entities causally or spatiotemporally related in any way to the existence of complex macro-consciousness. This can be illustrated by panpsychist versions of the conceivability argument and the knowledge argument—-think of microphenomenal zombies (Goff 2009) or a physically and micro-phenomenally omniscient Mary (Chalmers 2016).

Emergent panpsychism is the view that macro-consciousness is not constituted by configurations of micro-conscious entities, but causally generated by (or strongly emergent from) them. This view faces a problem of macro-mental causation analogous to dualism's problem of mental causation: emergent macro-consciousness would be rendered explanatorily

\footnotetext{
${ }^{8}$ Note that panpsychism does not imply that physical world is fully constituted by phenomenal properties alone. It is also compatible with it being partially constituted by fundamental, non-phenomenal relations, such as spatiotemporal or causal relations. The view that the physical world is constituted by phenomenal properties and fundamental, non-phenomenal relations is known as impure panpsychism. The view that the physical world is constituted by only phenomenal properties is known as pure panpsychism (Strawson 2006b, Chalmers forthcoming).
} 
redundant ${ }^{9}$ assuming all physical structure is already realized by micro-consciousness. Positing additional structure for which distinct macro-consciousness could be the realizer would bring emergent panpsychism into conflict with the principle of physical (or at least microphysical) causal closure.

In this way, the combination problem threatens to undermine the motivation for Russellian panpsychism. It appears to show that the view does not avoid the problems of physicalism and dualism after all; rather, it merely moves them and has them reappear in a different guise.

\section{$4 \quad$ IIT and the Combination Problem}

IIT is a theory with both empirical and metaphysical aspects. On the one hand, it proposes an empirical correlate of consciousness: all and only conscious systems are maxima of $\Phi$. On the other hand, it aims to explain why this correlation holds. Tononi argues that the correlation follows a priori from a set of phenomenological axioms, truths about consciousness which are self-evident upon introspection (Tononi, Albantakis, and Oizumi 2014).

The correlational claim, that maximum $\Phi$ is the correlate of consciousness, is empirically testable. Although $\Phi$ can be precisely calculated for complex systems only in theory, insofar as it can be estimated, it predicts which kinds of alterations in the brain would lead to a loss of consciousness (namely those that reduce the $\Phi$ of a brain area below the $\Phi$ of its parts). It is also verifiable in terms of how well it accounts for pre-existing data about consciousness. IIT accounts for why an area of the brain such as the cerebellum is not conscious, even though it has more neurons than the cerebrum, why deep sleep and epileptic seizures lead to loss of

\footnotetext{
${ }^{9}$ Perhaps outright epiphenomenal: overdeterminism may not be an option for emergent panpsychism, as it may not be possible for one structural property to have two distinct sufficient realizers (microphenomenal properties plus an emergent macrophenomenal property) as opposed to two distinct sufficient causes.
} 
consciousness even though neural activity remains high or increases, and a number of other facts that puzzle neuroscientists. ${ }^{10}$ Other proposed correlates of consciousness, such as activation in specific brain areas or neural oscillations in a specific frequency range, all arguably seem to be absent in some clearly conscious states or present in some unconscious ones (Tononi and Koch 2015: pp. 3-4).

The explanatory claim, that the correlation follows a priori from phenomenological axioms, is mainly supported by appeal to philosophical argument. If the explanatory claim is correct, then IIT could potentially solve the combination problem on its own. The a priori connection would eliminate all epistemic gaps, and the Exclusion postulate would eliminate the problem of causal exclusion (this will be discussed in more detail below). The philosophical case for the explanatory claim is, however, somewhat contentious. ${ }^{11}$ It is worth considering, therefore, whether the empirically testable, purely correlational claim could support a solution to the combination problem without commitment to the explanatory claim. I will suggest two ways in which the correlational claim can be combined with metaphysical approaches to combination that have been developed independently of IIT.

The phenomenal bonding view (Goff 2016) is a proposal for a solution to the combination problem for constitutive panpsychism. According to this view, some physical relations (such as spatiotemporal or causal relations) have their own intrinsic nature which is not reducible to the intrinsic properties of their relata. Physics is silent about the intrinsic nature of these relations, just as it is silent about the intrinsic nature of physical relata. Via introspection, we

\footnotetext{
10 The cerebellum has low interconnectivity between neurons despite having a large number of them (Tononi 2008: 221), and under epileptic seizures and deep sleep $\Phi$ strongly decreases even though activity increases or remains high (Tononi 2008: 223).

${ }^{11}$ Some complain that the alleged phenomenological axioms are less than self-evident (e.g., Cerullo 2015). Some argue that the empirical postulates are not adequately supported (e.g., Schwitzgebel 2015: section 2, concerning Exclusion). There might also be multiple ways of translating the empirical postulates into a mathematical formula (Tegmark 2016). Chalmers (2016) claims that IIT is best seen as a providing a fundamental, a posteriori law of nature specifying when combination occurs, but he does not specify precisely how he thinks Tononi's a priori justification fails.
} 
have access to the intrinsic nature of some physical relata (i.e., the phenomenal properties of our own brains), but we have no access to the intrinsic nature of physical relations. According to the phenomenal bonding view, if we knew the intrinsic nature of the kind of relation that connects the particles in our brain, we would see that the existence of macro-consciousness is indeed entailed by the existence of micro-conscious entities thus related.

One of the main challenges for the phenomenal bonding view is to specify which physical relation the phenomenal bonding relation could correspond to (Chalmers 2016). The phenomenal bonding relation must be a physical relation which holds within all and only systems where it is plausible that mental combination takes place. Goff suggests that the spatial relation is the phenomenal bonding relation. This would entail that all phenomenal properties which are spatially related are also co-conscious-experienced together from a single subjective point of view - or that every thinkable object (group of particles) is conscious as a whole (in the first sense). Most panpsychists (including Strawson (2006a: 26) and Tononi and Koch (2015: 11)) reject this kind of universalism - they want to restrict unified consciousness to just some kinds of systems, including brains and other biological systems and perhaps also lower level natural objects like minerals or molecules, some artificial systems such as future computers and robots, etc. ${ }^{12}$ There is no obvious candidate for a physical relation which gives this result.

\footnotetext{
12 What is the argument against universalism about combination? The view is clearly highly counterintuitive, but so is panpsychism itself (at least for many people of a broadly Western cultural background), so this should not count for too much. One more substantive worry with universalism is that it is very hard to imagine what it could be like to be an aggregate such as, say, the combination of my toe and a piece of my shoe, an arbitrary $30 \%$ of the brain area that supports my consciousness, or the set of two people fighting. Granted, it is also very hard to imagine what it is like to be a fundamental particle. But it is a different challenge to imagine what it is like to be a simple but unified thing than to imagine what it would be like to be a highly disunified thing. Phenomenological simplicity seems hard to imagine mainly because our power of imagination is limited, whereas phenomenological disunity or incoherence seems hard to imagine because it is hard to even make sense of. The experience of systems such as "my toe and a piece of my shoe" or "an arbitrary $30 \%$ of the brain area that supports my consciousness", and "the set of two people fighting" would have to be deeply incoherent. In the case of "the set of two people fighting", it would involve being conscious of contradictory thoughts (person 1 is thinking "person 2 is wrong", person 2 is thinking "person 2 is not wrong" and the aggregate is having both thoughts). In the case of " $30 \%$ of a
} 
IIT tells us what the phenomenal bonding relation could be. If maximal $\Phi$ is the correlate of (unified) consciousness, then the phenomenal bonding relation would be equivalent to a certain kind of causal relation: causal relations that relate elements within systems with maximal $\Phi$. One might wonder why the intrinsic nature of causal relations would depend on whether or not they are part of systems with maximal $\Phi .{ }^{13}$ But the most important thing for the phenomenal bonding view is that there exists some natural, not highly disjunctive kind of physical relation, that does not entail universalism, and that could possibly be identified as the phenomenal bonding relation.

The fusion view (Seager 2010, 2016; Mørch 2014) is an approach to the combination problem for emergent panpsychism. According to this view, the emergence of macro-consciousness is not synchronic - emergent macro-consciousness does not exist on top of, and at the same time as, an underlying micro-conscious base. Rather, the emergence is diachronic - emergent macro-consciousness succeeds and replaces the set of microphenomenal properties that gives rise to it. The generation of macro-consciousness happens as fusion: under certain conditions, microphenomenal properties fuse or blend together to form a new macro-conscious unity. The fusion view avoids the problem of macro-mental causation: if macro-consciousness replaces micro-consciousness (i.e., micro-consciousness transforms into macro-consciousness), it is the

brain area", it would seem to involve something like thinking $30 \%$ of a thought, or having $30 \%$ of a feeling, which is not clearly possible. There is nothing similarly paradoxical about the idea of a very simple but still coherent experience. This objection is clearly not definitive - there are probably ways for universalists to respond. But for those who worry about whether there could be a fully satisfactory response to this and other objections to universalism, IIT gives a way of avoiding it altogether.

13 Chalmers notes (2016: section 6.3) that relations such as those specified by IIT could be the phenomenal bonding relation, but objects that these relations are derivative and not fundamental. He claims that a solution to the combination problem in terms of phenomenal bonding and something like IIT gives rise to a new problem: how do fundamental causal relations (proto-bonding relations) become phenomenal bonding relations when they take on IIT-like character? A phenomenal bonding theorist could perhaps respond by renewed appeal to our ignorance of the intrinsic nature of physical relations: if we knew the intrinsic nature of causal relations, we would see how it works. It could also be suggested that there is a law of nature according to which the intrinsic nature of causal relations will transform into the kind of nature that supports phenomenal bonding when they become included in a system with maximal $\Phi$. This would move the phenomenal bonding view at least partially into the category of emergent panpsychism but, like the fusion view, it would nevertheless seem to avoid epiphenomenalism. 
sole candidate realizer for the physical structure with which it is correlated. It is hard to see how a synchronic emergence view can get around the same problem.

The main challenge for the fusion view is to find a physical correlate of mental fusion. Seager $(2010,2016)$ claims that quantum entanglement and the formation of black holes are physical examples of fusion. In both entangled systems and black holes, the constituents lose their individuality and are supplanted by an irreducible new unity - a "large simple". But nothing like this seems to be going on in the brain. I have argued (Mørch 2014) that mental fusions do not need to be partless simples, they only need to be wholes which are metaphysically prior to their parts. But no parts of the brain clearly appear to be prior to their parts either.

IIT itself is a kind of fusion view. According to the Exclusion postulate, only maxima of $\Phi$ are conscious, hence, whenever a complex system becomes conscious by gaining maximal $\Phi$ its parts will lose micro-consciousness (in the first sense; they will remain conscious in the third sense, as defined in the introduction). $\Phi$ measures not only information but also integration, and integration is a form of unity. ${ }^{14}$ IIT thus defines a sense in which physical systems can be more unified than their parts, and thereby be said to be prior to their parts, as fusions should be. One might wonder whether fusions should not ideally be characterized by an even stronger form of unity. ${ }^{15}$ But the most important thing for the fusion view is that there is some property which could serve to identify fusions from the physical point of view, which is empirically detectable, but does not entail any revisionary physical hypotheses (such as quantum entanglement at the brain level or other kinds of strong physical emergence).

\footnotetext{
${ }^{14}$ Recall, high integration means that the parts of a system are highly causally interconnected, and thereby bound together as a unit.

15 Tononi claims that maximal $\Phi$ corresponds to maximal causal power. This would give fusions a very strong form of metaphysical priority. But the view that $\Phi$ corresponds with causal power depends on a distinctive and controversial metaphysical view about causation (see Hoel, Albantakis, and Tononi 2013).
} 


\section{The Coarse-Graining Problem}

Unfortunately, there is a problem which gets in the way of any solution to the combination problem in terms of IIT: the coarse-graining problem. This problem stems from the way IIT identifies the spatiotemporal grain of consciousness.

IIT not only selects a set of elements which, when regarded as a system, gives maximal $\Phi$. It also selects a spatiotemporal grain (Hoel et al. 2013, 2016). One might regard the brain (or brain area that correlates with our consciousness) as a system consisting of elements at the smallest spatial grain - as a system of subatomic particles. Calculating on this basis will result in certain value of $\Phi$. But one might also regard the brain as a system consisting of elements at a coarser spatial grain, such as a system of neurons or groups of neurons. This will result in a higher value of $\Phi$ (Hoel et al. 2016: pp. 11-12). One can also vary the temporal grain. One might regard each state of a system as lasting one nanosecond and calculate how much integrated information the present nanosecond-long state has about the immediate past and future nanosecond states. Or one might regard each state as lasting for milliseconds, and calculate how much integrated information the present milliseconds-long state has about the immediate past and future milliseconds long states. For the brain, a coarser temporal grain (perhaps corresponding to the time it takes for neurons to fire) will result in higher $\Phi$.

If a maximally integrated system exists at a certain spatiotemporal grain, the structure below that grain will not matter to the quality of the experience of that system (Tononi and Koch 2015: footnote 9). For this reason, IIT allows for multiple microphysical realizability of systems with identical consciousness. If the $\Phi$ of the brain peaks when the brain is considered as a system of neurons, it will not matter to the character of its experience whether the microstructure of the neurons is carbon-based or silicon-based as long as they function identically at the neuron level. 
This leads to a conflict with Russellian panpsychism, as follows. Dispositions are causal properties involving relations between circumstances (or inputs) and manifestations (or outputs), such as "will repel electrons if nearby", "will attract massive particles in proportion to their distance", or "will travel at the speed of light if unobstructed". Every major theory of causation entails that the dispositions of things are determined by their intrinsic properties together with the laws of nature. Or more precisely, they entail that dispositions are thus determined given that things have any intrinsic properties at all and that these properties are not epiphenomenal. ${ }^{16}$ According to the causal powers view (Shoemaker 1980; Ellis 2001; Bird 2007), dispositions are determined by the intrinsic, or intrinsically grounded, causal powers of individual things (these powers in turn determine the laws). ${ }^{17}$ According to realism about laws (Dretske 1977; Tooley 1977; Armstrong 1978), dispositions are determined by irreducible governing laws, and it is natural to think that the laws apply to things in virtue of their intrinsic properties. ${ }^{18}$ According to the regularity theory (Hume 1739-1740/2000; Lewis 1973), the dispositions of things depend on their intrinsic, qualitative properties and contingent regularities involving properties of the same type instantiated across the actual or possible world(s) (the laws are regarded as reducible to these regularities).

According to Russellian panpsychism, the intrinsic properties of things are all phenomenal properties, ${ }^{19}$ and phenomenal properties are not epiphenomenal. It follows that if Russellian

\footnotetext{
16 Theories such as ontic structural realism (Ladyman and Ross 2007) deny that intrinsic properties exist. It also seems coherent to suppose that dispositional properties are ungrounded in the way ontic structural realists claim, while claiming that intrinsic properties such as phenomenal properties exist but are epiphenomenal.

17 According to one version of the causal powers view, dispositional monism, all properties are purely dispositional, i.e., have no categorical (or qualitative) aspects or grounds. According to another version, the identity view (also known as the powerful qualities view), all properties are both dispositional and categorical (Martin and Heil 1999; Strawson 2008). Russellian panpsychism generally takes phenomenal properties to be categorical and would accordingly be incompatible with dispositional monism, but it would still be fully compatible with the identity view.

${ }^{18}$ Armstrong explicitly holds that laws of nature consist in relations between categorical, i.e., intrinsic, universals. 19 This is not to say that all intrinsic properties are phenomenal, according to Russellian panpsychism, only the intrinsic properties of individual things. As discussed above, Goff's phenomenal bonding view says that some relations, namely spatial relations, have their own non-phenomenal intrinsic properties responsible for combination. If IIT is combined with the phenomenal bonding view, in the way I proposed above, then causal relations also involve this kind of intrinsic properties.
} 
panpsychism is true, dispositions at least nomologically supervene on phenomenal properties. That is to say, given that the laws of nature (whether irreducible, derived from intrinsic powers, or reducible to contingent regularities) remain the same, then how things are disposed to behave is determined by what they are intrinsically like, i.e., their phenomenal properties.

If dispositions nomologically supervene on phenomenal properties, then there cannot be things with the same phenomenal properties but different dispositions given the same laws. But according to IIT's coarse-graining principle, there can be things with the same phenomenal properties but different dispositions given the same laws, namely coarse-grained systems such as silicon and organic brains: at the coarse-grained level, they are functionally identical, but at the fine-grained, microphysical level, they have different dispositions corresponding to their different silicon and carbon constituents. It follows that Russellian panpsychism is false - some dispositions do not nomologically supervene on phenomenal properties. ${ }^{20}$

One might think this conflict can simply be resolved by supposing that although silicon brains and organic brains have identical macrophenomenal properties, they have different microphenomenal properties. Silicon neurons (or molecules/atoms) would have silicon-type micro-experience, while the organic neurons (or molecules/carbon atoms) would have different carbon-type micro-experience, while both constituting the same human macro-experience. The identical human macro-experiences would nomologically determine identical coarse-grained

\footnotetext{
${ }^{20}$ Note that Russellian panpsychism does not require that all physical properties nomologically supervene on phenomenal properties, only that dispositional properties do. Physical structure as a whole may also consist of arguably non-dispositional relations, such as spatial relations (which may be part of how dispositions manifest or the circumstances that trigger their manifestation). As noted above, these relations might be fundamental (see footnote 8), or perhaps supervene on non-phenomenal, intrinsic properties of relations such as those involved in phenomenal bonding.

Given this, one might think the differences between silicon and carbon brains come down to differences in non-phenomenal relations rather than differences in dispositions. However, at the fundamental level, silicon and carbon consists of different numbers and ratios of fundamental particles such as quarks, electrons and so on. Each type of fundamental particle has its own fundamental and unique dispositions. Therefore, silicon and carbon brains must be regarded as having different dispositions.
} 
macrophysical dispositions, while the different neuron (or molecule/atom) experiences would nomologically determine the different microphysical dispositions.

But this is ruled out by IIT's Exclusion postulate, according to which consciousness never overlaps - only the system with maximal $\Phi$ is conscious. Neurons (or molecules/atoms) cannot have different experiences if they are excluded from having experiences of their own in the first place. Hence, IIT is not compatible with Russellian panpsychism in view of the coarsegraining principle and the Exclusion postulate.

It might seem that the best way of rendering IIT and Russellian panpsychism compatible would therefore be to abandon one of these principles. But abandoning either leads to both philosophical and empirical problems.

\section{Abandoning Exclusion}

Rejecting Exclusion leads to a prima facie very undesirable proliferation of consciousness. Nations, the internet, the galaxy and the universe all have non-zero, but non-maximal, $\Phi$ and would therefore be conscious without Exclusion. There would also be multiple overlapping consciousnesses within the brain. Not only would each neuron be conscious, there would also be one consciousness associated with almost any combination of neurons (the brain, the brain minus one neuron, minus two neurons, minus two other neurons, and so on). In other words, we would get a serious case of the problem of the many. For those who are motivated to combine IIT with Russellian panpsychism in order to avoid universalism with respect to phenomenal bonding, this consequence should be unacceptable.

Rejecting Exclusion is also empirically problematic for IIT. As mentioned, the empirical case for IIT is largely based on data about when normal human consciousness disappears and reappears according to reports, such as in deep sleep, general anesthesia, seizures and coma. 
These states do not leave the brain with zero $\Phi$ - our consciousness seems to disappear (which according to IIT would equal disintegrating into multiple lesser consciousnesses) long before $\Phi$ reaches zero. What explains this? IIT is not entirely clear on this point. One possible explanation is that low, but non-zero, $\Phi$ still correlates with some dim form of consciousness but not with memory or reportability. ${ }^{21}$ But this seems somewhat stipulative - why would it necessarily be the case that low $\Phi$ states cannot be remembered or reported? It might also be very worrisome if true about anesthesia! ${ }^{22}$ An alternative, more systematic explanation would be to appeal to the Exclusion postulate: our consciousness disappears because the $\Phi$ of the normally conscious brain area goes below the $\Phi$ of neurons, neuron groups, or other subsystems that constitute it. Given Exclusion, these subsystems will then become individually conscious instead (each to a much lesser degree) because they are now the maxima. It is not clear whether the $\Phi$ of sleeping or anesthetized brain areas is actually lower than the $\Phi$ of any subsystems given the practical difficulties with measuring $\Phi$ precisely, this is still an open empirical question. But by abandoning Exclusion, this simple and elegant explanation will be ruled out regardless of the empirical outcome. In view of these problems, abandoning Exclusion in order to render IIT compatible with Russellian panpsychism looks like it would not be worth the costs.

\section{Abandoning Coarse-Graining}

Instead of Exclusion, one could consider abandoning coarse-graining. This would imply that when calculating the $\Phi$ of a system, one should always regard it as a system of fundamental particles. If so, silicon and organic brains would have differences in their experiences on which the differences in their microphysical dispositions could nomologically supervene.

\footnotetext{
${ }^{21}$ Tononi and Koch (2015: 13) gesture toward such a view.

${ }^{22}$ It could be that consciousness during anesthesia is not painful, or if it is, that it is just very dimly painful and therefore nothing to worry about—-but there is no obvious reason to think this would necessarily be the case.
} 
But abandoning coarse-graining would also lead to both philosophical and empirical problems. Firstly, the view that our experience is coarse-grained is not only motivated by IIT. It is widely regarded as a phenomenological datum. When we look at our own experience, it directly, phenomenologically appears to have a certain spatiotemporal structure, and this structure appears to be much more coarse-grained than the microphysical structure of our brain. As already noted, we do not appear to experience as many distinctions (or other sort of grains) within our experience as there are particles (or other sorts of grains) in our brain. Furthermore, our experiences appear to contain far fewer temporal distinctions than microphysical processes in the brain. The shortest distinguishable experiences appear to last for at least some milliseconds, but microphysical events in the brain last nanoseconds or less.

This is the basis for the so-called grain problem in philosophy of mind known from Lockwood (1993) and Sellars $(1965,1971)$ : the grain of experience does not correspond to the microphysical grain of the brain. The conclusion often drawn from the grain problem is that human consciousness needs an irreducibly macrophysical correlate, which is precisely what it gets with IIT's coarse-graining principle, but loses without it.

Secondly, rejecting coarse-graining would lead to an empirical problem. As noted, if we regard the brain as a system of particles, it will have lower $\Phi$ than if we regard it as a system of neurons. And it will probably also have lower $\Phi$ than small neuron groups, individual neurons or perhaps even molecules or atoms in the brain. Therefore, without coarse-graining, we might have to say that small neuron groups, neurons, molecules or atoms in the brain are conscious rather than any larger brain area as a whole. This would result in at least thousands (perhaps billions) other consciousnesses in our brains, each of which as highly conscious as our own. This seems highly implausible (as another version of the problem of the many, although in this case the many do not spatially overlap) and does not fit any natural interpretation of empirical data. With coarse-graining, in contrast, $\Phi$ will peak only in a few locations, and the highest 
peak would be much higher than the others, so there will only be one most advanced consciousness in the brain. ${ }^{23}$

Hence, abandoning coarse-graining seems out of the question for IIT. What I will now suggest is that, in order to render IIT compatible with Russellian panpsychism, there is no need to wholly abandon either coarse-graining or the Exclusion postulate. Instead, it would suffice to merely modify either one of the principles, in ways I will now describe.

\section{Modifying Exclusion}

One way of avoiding the coarse-graining problem is to modify the Exclusion postulate by relativizing it to spatiotemporal grains. Instead of saying that consciousness never overlaps, IIT could say that (1) consciousness never overlaps within the same spatiotemporal grain, and (2) there is consciousness only at grains with higher $\Phi$ than any grain below. This would entail that the brain, regarded as a coarse-grained system, will have overlapping consciousness at the finest, microphysical grain (as systems at the finest grain vacuously satisfy clause (2) given that there is no grain below). In two brains with different fine-grained constituents, such as silicon and carbon, the overlapping micro-consciousness will also be different. Differences in microphysical dispositions could then nomologically supervene on these differences in microconsciousness.

This grain-relativized Exclusion postulate avoids the problems that result from wholly abandoning it. It will not prevent human consciousness from disappearing in deep sleep, general anesthesia and so on before $\Phi$ goes to zero. Human consciousness would disappear when the $\Phi$ of its correlate brain area goes lower than the $\Phi$ of individual neurons or smaller

\footnotetext{
${ }^{23}$ At least in normal circumstances - according to IIT, split brain (severed corpus callosum) patients will have one consciousness in each hemisphere, with almost the same $\Phi$. It is also possible that our consciousness temporarily splits into two in cases such as automatic (absent-minded) driving.
} 
neuron groups, because Exclusion is still in effect within this grain. For the same reason, there will not be overlapping consciousness in overlapping systems of neurons (the brain minus one neuron, the brain minus two neurons, two other neurons, etc.). It will not result in internet, galaxy or cosmic consciousness, because the brain has maximal $\Phi$ all grains considered. The internet, the galaxy and the cosmos will not have higher $\Phi$ than the brain if we regard them as being made of entities at the same grain as neurons, nor if we regard them as being made of coarser-grained entities such as computers or stars or finer-grained entities such as atoms. At smaller scales, there could be other grains between the subatomic and neuron level that increase $\Phi$ (such as systems of molecules), resulting in more than one level of micro-consciousness, but there would not be arbitrarily or absurdly many such levels.

This modification of Exclusion is only compatible with constitutive Russellian panpsychism. If microphenomenal and macrophenomenal properties are entirely distinct, as per the emergent view, then microphenomenal properties at lower grains would causally exclude macrophenomenal properties at higher levels with maximal $\Phi$. But the idea that coarse-grained macrophenomenal properties are constituted by overlapping fine-grained microphenomenal properties leads to another problem.

Say I have an experience of a tiny patch or "pixel" of phenomenal green, the smallest patch of green that is possible given the grain of my experience. This green patch will be completely uniform green for me, because my experience cannot contain any complexity below its own smallest grain. Now, this uniform green patch will actually be constituted by microphenomenal properties at a smaller grain, for example, even smaller patches of blue and yellow that are the experiences of the particles in my brain (or some other kinds of particle experiences that we cannot imagine). But then it seems my experience of green is both uniform (i.e., partless) and complex, made of distinct blue and yellow (or otherwise non-green) parts, at the same time. 
Many Russellian panpsychists, along with non-reductionists about consciousness in general, are motivated by the principle that there is no appearance/reality distinction for phenomenal properties (if an experience appears to be of uniform green, then it is of uniform green, phenomenally speaking). Given this principle, it would not be possible for the same phenomenal property to appear either uniform green or complex yellow/blue (or otherwise nongreen) depending on the grain. If the same property appears in all of these ways, then the same property would also be both uniform and non-uniform, which is contradictory. Hence, this way of rendering IIT and Russellian panpsychism compatible seems to come at the cost of having to introduce a kind of appearance/reality distinction for phenomenal properties which may be in tension with Russellian panpsychism's initial motivation.

Note, however, that the same kind of problem would confront constitutive panpsychism independently of this proposal, in view of the grain problem alone. The grain problem, discussed above, also claims - on a general phenomenological basis in contrast to IIT's more specific and theoretical one ${ }^{24}$ - that some macrophenomenal properties appear uniform. But according to constitutive panpsychism, all macrophenomenal properties are constituted by microphenomenal properties and hence really complex. This problem is a version of what is known as the revelation problem and can be regarded as a further aspect of the combination problem for constitutive panpsychism (Goff 2006; Chalmers 2016).

Hence, this is not a problem that results from this proposal in particular. It might still, however, be regarded as a limitation of the proposal, because it means that there is an important aspect of the combination problem that this way of combining IIT with Russellian panpsychism does

\footnotetext{
${ }^{24}$ As discussed above, IIT's coarse-graining principle may by partially justified on the basis of the grain problem, but it also has an independent theoretical motivation, according to which coarse-graining is required for $\Phi$ to increase in the right places in the brain.
} 
nothing to solve. The revelation problem may still be resolvable in other ways, of course, though this has arguably not yet been clearly demonstrated..$^{25}$

\section{Modifying Coarse-Graining}

Another way of avoiding the coarse-graining problem, that also avoids the problems associated with overlapping uniform and complex experiences, is to modify the coarse-graining principle itself. This modification starts from noticing a certain tension between two aspects of the combination problem.

The grain problem, as already discussed, says that macro-consciousness has too little structure to reflect the full microphysical structure of our brains. But there is also another aspect of the combination problem known as the palette problem (Chalmers 2016: Sect. 7). According to this problem, macro-consciousness has too many qualities. In physics, we find a limited number of fundamental particles (about 17, according to the standard model). This suggests a correspondingly limited number of basic microphenomenal qualities. In our experience, however, we find an apparently endless number of different phenomenal qualities (colors, sounds, emotions and so on). It is hard to see how all these qualities can result (without radical emergence) just from combining a small number of basic microphenomenal qualities in different ways.

If macro-consciousness has too little structure, but too many qualities, to reflect its microphysical correlate, this suggest that the missing structure is somehow encoded in the extra qualities - that microphysical structure is reflected in macrophenomenal qualities as opposed

\footnotetext{
${ }^{25}$ Proposed solutions to the revelation problem include Strawson (2006b: 252), Chalmers (2016: 190) and Brogaard (2016: 147-150). For criticism, see Goff (2015) on Strawson, and Brogaard (2016) on Chalmers. It is also worth noting that Russell seemed to take our acquaintance with phenomenal properties to be compatible with some types of appearance/reality distinctions, as illustrated by phenomenal continua cases in which different phenomenal properties can be falsely judged to be identical (Wishon 2017) (thanks to an anonymous referee for pointing this out). One might think acquaintance could therefore also be compatible with the kind of appearance/reality distinction implied by this proposal.
} 
to macrophenomenal structure. Instead of having one little distinct patch in our experience corresponding to every particle in the brain, perhaps a single coarse-grained quality (like a patch of color, or an emotion) reflects complex microphysical structure in virtue of the many complex ways it differs from other possible macrophenomenal qualities.

Accordingly, IIT could be modified to say that fine-grained microphysical structure matters to the quality, but not the structure, of experiences. Or in other words, that macrophenomenal structure is multiply microphysically realizable, ${ }^{26}$ but macrophenomenal qualities are not. If your organic neurons were to be replaced by functionally identical silicon neurons, then your experience would have the same (contrastive and motivational) structure but different qualities (i.e., a shifted spectrum). For example, for the silicon brain, tomatoes and grass would be experienced as having color-like qualities we cannot imagine, but they would be as different from each other as red and green are for us, and they would have pain and pleasure-like qualities which feel different from ours, but they would still feel equally bad and good. The fact that silicon and organic brains would have the same macrophenomenal structure could account for why these systems have the same dispositions at the macrolevel. That they have different, shifted qualitative spectra could perhaps account for why they have different microphysical dispositions (i.e., why they respond differently to microscopic measurement, decompose in different ways, etc.).

The distinction between quality and structure need not be sharp. As long as there are some aspects of coarse-grained experiences that fall neatly into the qualitative category, others may belong to both. One might think coarse-grained physical structure correlates with the structural aspects of the content of coarse-grained experiences and those qualitative aspects that are not

\footnotetext{
${ }^{26}$ According to Russellian panpsychism, there is a sense in which the mental realizes the physical. But there is also realization within the physical, in another sense of the term. To say that macro-consciousness is multiply microphysically realizable given Russellian panpsychism is to say that the macrophysical structure realized by macro-consciousness in the metaphysical sense is multiply realizable in the physical sense.
} 
separable from the structural aspects (those aspects for which a shifted spectrum is not possible), whereas fine-grained physical structure correlates with those qualitative aspects that are separable from phenomenal structure (those aspects for which a shifted spectrum is possible).

Many questions remain as to precisely how microphysical causal structure could be encoded or grounded in unstructured qualities, as well as about how this could be incorporated into the formalism of IIT. ${ }^{27}$ I have only shown that there is some extra qualitative information in one place that can be connected to missing structural information in another place, and there is nothing that immediately rules out that there is some way of translating one to the other. Given this, it at least looks more plausible that IIT and Russellian panpsychism can be combined.

\section{Conclusion}

I have suggested two ways of resolving the coarse-graining problem and rendering IIT and Russellian panpsychism compatible. These suggestions involve substantive modifications of some basic principles of IIT, either the Exclusion postulate or the coarse-graining principle. Given one of these modifications, IIT would support (significant progress towards) a solution to the combination problem for Russellian panpsychism. IIT would support this solution either on its own, in view of its explanatory claim according to which the principles of mental combination are a priori deducible from phenomenological axioms, or on the basis of its purely correlational claim taken together with either the phenomenal bonding view or the fusion view of mental combination.

\footnotetext{
${ }^{27}$ Note that IIT as it stands makes no distinction between structural and qualitative aspects of the content of consciousness. IIT distinguishes between the overall level, or amount, of consciousness (which corresponds to the overall $\Phi$ of a system) and the content of consciousness (which corresponds to the precise causal structure of a system, in IIT called conceptual structure). My proposal is to make a further distinction, within content, between structural and qualitative aspects. This does not involve any change to the way coarse-graining affects overall $\Phi$.
} 
Both of my suggested modifications leave some further questions open. The suggested modification of the Exclusion postulate is in tension with the claim that phenomenal qualities necessarily are as they appear and thereby fails to resolve the aspect of the combination problem known as the revelation problem. The suggested modification of the coarse-graining principle assumes mysterious links between qualities and structure. In the absence of a clear solution to the revelation problem, perhaps the mystery of the latter proposal is preferable to the tension of the former. Modifying the Exclusion postulate might also be more at odds with Tononi’s own philosophical case for IIT.

IIT has many philosophical aspects which have not been discussed here - as noted, I have set the theory's central philosophical claims mostly aside and mainly considered the significance of its empirically testable correlational claim, i.e., the claim that maximal $\Phi$ is the correlate of consciousness. IIT as a whole should be subjected to closer philosophical scrutiny if the theory is to fully support a solution to the combination problem. On the one hand, one might find even more sources of tension with Russellian metaphysics within IIT. On the other hand, one might discover other aspects of IIT that could contribute to even further advancing the case for a panpsychist solution to the mind-body problem. $^{28}$

\footnotetext{
${ }_{28}$ Many thanks to Giulio Tononi, Erik Hoel, David Chalmers, Torin Alter, Luke Roelofs, Neil Mehta, Kelvin McQueen, and participants and referees at the conferences "IIT: Foundational Issues" (NYU 2015), "Nonphysicalist Views of Consciousness" (Cambridge University 2016), "The Science of Consciousness" (Tucson, Arizona 2016) and "Minds Online" (2016) for helpful comments on this paper.
} 


\section{Bibliography}

Alter, Torin, and Yujin Nagasawa. 2012. What Is Russellian Monism? Journal of Consciousness Studies 19 (9-10): 67-95.

Armstrong, David M. 1978. A Theory of Universals. Universals and Scientific Realism Volume II. Cambridge University Press.

Barrett, Adam B. 2014. An Integration of Integrated Information Theory with Fundamental Physics. Frontiers in Psychology 5: 63.

Brogaard, Berit. 2016. In Search of Mentons. In Panpsychism: Contemporary Perspectives, eds. G. Brüntrup and L. Jaskolla. Oxford: Oxford University Press.

Bird, Alexander. 2007. Nature's Metaphysics: Laws and Properties. Oxford: Clarendon Press.

Cerullo, Michael A. 2015. The Problem with Phi: A Critique of Integrated Information Theory. PLOS Computational Biology 11 (9), e1004286.

Chalmers, David J. 1996. The Conscious Mind: In Search of a Fundamental Theory. New York: Oxford University Press. 2003. Consciousness and Its Place in Nature. In Blackwell Guide to Philosophy of Mind, eds. S. P. Stich and T. A. Warfield. Malden, MA: Blackwell. . 2009. The Two-Dimensional Argument against Materialism. In Oxford Handbook to the Philosophy of Mind, eds. B. P. McLaughlin and S. Walter. Oxford: Oxford University Press.

- 2015. Panpsychism and Panprotopsychism. In Consciousness in the Physical World: Essays on Russellian Monism, eds. T. Alter and Y. Nagasawa. New York: Oxford University Press.

- 2016. The Combination Problem for Panpsychism. In Panpsychism: Contemporary Perspectives, eds. G. Brüntrup and L. Jaskolla. Oxford: Oxford University Press.

— forthcoming. Idealism and the Mind-body Problem. In The Routledge Handbook of Panpsychism, ed. W. Seager Routledge.

Dretske, Fred I. 1977. Laws of Nature. Philosophy of Science 44 (2): 248-268.

Ellis, B. D. 2001. Scientific Essentialism. Vol. 113. Vol. 450 Cambridge University Press.

Goff, Philip. 2006. Experiences Don't Sum. Journal of Consciousness Studies 13 (10-11): $53-$ 61.

. 2009. Why Panpsychism Doesn't Help Us Explain Consciousness. Dialectica 63 (3): 289-311.

- 2015. Against Constitutive Russellian Monism. In Consciousness in the Physical World: Perspectives on Russellian Monism, eds. T. Alter and Y. Nagasawa Oxford University Press.

—. 2016. The Phenomenal Bonding Solution to the Combination Problem. In Panpsychism: Contemporary Perspectives, eds. G. Brüntrup and L. Jaskolla. Oxford: Oxford University Press.

Hoel, Erik P., Larissa Albantakis, William Marshall, and Giulio Tononi. 2016. Can the Macro Beat the Micro? Integrated Information across Spatiotemporal Scales. Neuroscience of Consciousness 2016 (1).

Hoel, Erik P., Larissa Albantakis, and Giulio Tononi. 2013. Quantifying Causal Emergence Shows That Macro Can Beat Micro. Proceedings of the National Academy of Sciences 110 (49): 19790-19795.

Hume, David. 1739-40/2000. A Treatise of Human Nature. In Oxford Philosophical Texts, ed. J. Cottingham. Oxford: Oxford University Press.Jackson, Frank. 1982. Epiphenomenal Qualia. Philosophical Quarterly 32 (April): 127-136.

—. 1986. What Mary Didn't Know. The Journal of Philosophy 83 (5): 291-295.

James, William. 1890. The Principles of Psychology. Vol. 1. London: Macmillan. 
- 1912. Essays in Radical Empiricism. New York, London, Bombay and Calcutta: Longmans, Green \& Co.

Kim, Jaegwon. 1988. Explanatory Realism, Causal Realism, and Explanatory Exclusion. Midwest Studies in Philosophy 12 (1): 225-239.

Koch, Cristof. 2012. Consciousness: Confessions of a Romantic Reductionist. Cambridge, MA: MIT Press.

Kripke, Saul A. 1980. Naming and Necessity. Cambridge, MA: Harvard University Press.

Ladyman, James, and Don Ross. 2007. Every Thing Must Go: Metaphysics Naturalized. Oxford: Clarendon Press.

Langton, Rae. 1998. Kantian Humility: Our Ignorance of Things in Themselves. Oxford: Oxford University Press.

Lewis, David. 1973. Causation. Journal of Philosophy 70 (17): 556-567.

Lockwood, Michael. 1993. The Grain Problem. In Objections to Physicalism, ed. H. M. Robinson Oxford University Press.

Mach, Ernst. 1886. Beiträge Zur Analyse Der Empfindungen. Jena: Verlag von Gustav Fischer.

- 1894. Populärwisschenschaftliche Vorlesungen. Reprint of the fifth edition, Vienna: Böhlau Verlag, 1923.

- 1905. Erkenntnis Und Irrtum. Fifth edition translated as Knowledge and Error, Dordrecht: Reidel, 1976.

Martin, C. B., and John Heil. 1999. The Ontological Turn. Midwest Studies in Philosophy 23 (1): 34-60.

Mørch, Hedda Hassel. 2014. Panpsychism and Causation: A New Argument and a Solution to the Combination Problem (Doctoral Dissertation), Departement of Philosophy, Classics, History of Art and Ideas, University of Oslo, Oslo.

Nagel, Thomas. 1979. Panpsychism. In Mortal Questions. Cambridge: Cambridge University Press.

Nagasawa, Yujin, and Torin Alter. 2015. Consciousness in the Physical World: Perspectives on Russellian Monism. Oxford University Press.

Papineau, David. 2001. The Rise of Physicalism. In Physicalism and Its Discontents, eds. C. Gillett and B. Loewer. Cambridge: Cambridge University Press.

Pereboom, Derk. 2015. Consciousness, Physicalism, and Absolutely Intrinsic Properties. In Consciousness in the Physical World: Perspectives on Russellian Monism, eds. T. Alter and Y. Nagasawa Oxford University Press.

Russell, Bertrand. 1927. The Analysis of Matter. London: Kegan Paul, Trench, Trubner \& Co. Schopenhauer, Arthur. 1966a. The World as Will and Representation Vol. 1. Translated by E. F. J. Payne. New York: Dover.

Schopenhauer, Arthur. 1966b. The World as Will and Representation Vol. 2. Translated by E. F. J. Payne. New York: Dover.

Schwitzgebel, Eric. 2015. If Materialism Is True, the United States Is Probably Conscious. Philosophical Studies 172 (7): 1697-1721.

Seager, William. 1995. Consciousness, Information and Panpsychism. Journal of Consciousness Studies 2 (3): 272-288.

- 2006. The 'Intrinsic Nature' Argument for Panpsychism. Journal of Consciousness Studies 13 (10-11): 129-145.

- 2010. Panpsychism, Aggregation and Combinatorial Infusion. Mind and Matter 8 (2): 167-184.

- 2016. Panpsychist Infusion. In Panpsychism: Contemporary Readings, eds. G. Brüntrup and L. Jaskolla. Oxford: Oxford University Press.

Searle, John R. 2013. Can Information Theory Explain Consciousness? New York Review of Books 60 (1), 30-41. 
Sellars, Wilfrid S. 1965. The Identity Approach to the Mind-body Problem. Review of Metaphysics 18 (March): 430-51.

. 1971. Seeing, Sense Impressions, and Sensa: A Reply to Cornman. Review of Metaphysics 24 (March): 391-447.

Shoemaker, Sydney. 1980. Causality and Properties. In Time and Cause: Essays Presented to Richard Taylor, ed. P. van Inwagen. Dordrecht: Reidel.

Strawson, Galen. 2006a. Realistic Monism: Why Physicalism Entails Panpsychism. Journal of Consciousness Studies 13 (10-11): 3-31.

Strawson, Galen. 2006b. Panpsychism? Reply to Commentators with a Celebration of Descartes. Journal of Consciousness Studies 13 (10-11): 184-280.

- 2008. The Identity of the Categorical and the Dispositional. Analysis 68 (4): 271-282.

Stubenberg, Leopold. 2015. Russell, Russellian Monism and Panpsychism. In Consciousness in the Physical World: Perspectives on Russellian Monism, eds. T. Alter and Y. Nagasawa Oxford University Press.

Tegmark, Max. 2016. Improved Measures of Integrated Information. PLOS Computational Biology 12 (11).

Tononi, Giulio. 2004. An Information Integration Theory of Consciousness. BMC Neuroscience 5 (1): 42.

- 2008. Consciousness as Integrated Information: A Provisional Manifesto. The Biological Bulletin 215 (3): 216-242.

- 2011. Integrated Information Theory of Consciousness: An Updated Account. Archives Italiennes de Biologie 150 (2-3): 56-90.

Tononi, Giulio, Larissa Albantakis, and Masafumi Oizumi. 2014. From the Phenomenology to the Mechanisms of Consciousness: Integrated Information Theory 3.0. PLOS Computational Biology 10 (5), e1003588.

Tononi, Giulio, Melanie Boly, Marcello Massimini, and Christof Koch. 2016. Integrated Information Theory: From Consciousness to Its Physical Substrate. Nature Reviews Neuroscience 17 (7): 450-461.

Tononi, Giulio, and Christof Koch. 2015. Consciousness: Here, There and Everywhere? Philosophical Transactions of the Royal Society of London B: Biological Sciences 370 (1668), 20140167.

Tooley, Michael. 1977. The Nature of Laws. Canadian Journal of Philosophy 7 (4): 667-98.

Wishon, Donovan. 2015. Russell on Russellian Monism. In Consciousness in the Physical World: Perspectives on Russellian Monism, eds. T. Alter and Y. Nagasawa Oxford University Press.

Wishon, Donovan. 2017. Russellian Acquaintance and Frege's Puzzle. Mind 126 (502): 321370. 